\title{
Phytotoxic effect of chrome liquor on growth and chlorophyll content of Spirodela polyrrhiza L. Schleid
}

\author{
A sha Singh and Piyush M alaviya* \\ Department of Environmental Science, University of Jammu, Jammu-180006 (J\&K), INDIA \\ *Corresponding author. E-mail: piyushmalaviya@ rediffmail.com \\ Received:M arch 28, 2013; Revised received:April 10, 2013; Accepted: A pril 25, 2013
}

\begin{abstract}
The present study assessed the tolerance of S pirodela polyrrhiza (L.) Schleid (giant duckweed) exposed to different concentrations (5\%-100\%) of chrome liquor for 7 days. Physiological conditions of S.polyrrhizaplants were monitored daily by measuring fresh weight and chlorophyll-a and chlorophyll-b. Fresh biomass of Spirodela plant showed concentration and duration dependent reduction with minimum value $(5.71 \mathrm{~g})$ reported on $7 \mathrm{~d}$ at $100 \%$ tannery effluent concentration. Likewise, significant reduction in chlorophyll-a and chlorophyll-b content was observed in concentration-duration dependent manner with maximum reduction reported to be $99.8 \%$ and $99.6 \%$ respectively on $7 \mathrm{~d}$ at $100 \%$ effluent concentration in comparison to control.
\end{abstract}

Keywords: Chlorophyll, Chrome liquor, Spirodela, Tannery, Toxicity

\section{INTRODUCTION}

The tanning industry is one of the major consumers of water and chrome tanning is the most common type of tanning where a large amount of basic chromium sulphate is used. Tannery wastewater contains very high values of BOD, COD, total solids, chlorides, sulphates and chromium (Bajza and Vrcek, 2001). Chromium (Cr), in the spent chromium liquor from the tannery industry practicing classical chromium tanning method, may be as high as 1300-2500 $\mathrm{mg} \mathrm{L}^{-1}$ (Hafez and El-Manharawy, 2004; Malaviya and Singh, 2011). Exposure of Cr(VI) to humans may result in chrome ulcers, corrosive reaction at nasal septum, acute irritative dermatitis and allergic eczematous dermatitis (Tahir and Naseem, 2007). While evaluating the environmental impact of complex industrial wastewaters, in addition to physico-chemical analysis,toxicity testing helps to assess pollutant bioavailability, as well as in comprehensive understanding of synergistic toxic effects of different pollutants present in the wastewater. Integration of both chemical and biological approaches is therefore crucial to corroborate ecotoxicity testing (Kuczynskaet al., 2005; Mwinyihijaet al., 2006; Malaviya and Sharma, 2011).

Most studies with $\mathrm{Cr}$ toxicity have focused on the effects of $\mathrm{Cr}$ solution on plant tolerance, growth and survival with only a few studies (Vajpayee et al., 2001; Sinhaet al., 2002; Calheiroset al., 2008) conducted on toxicity of tannery effluent. In the present study,an attempt has been made to assess the toxic effects of different concentrations of chrome liquor on growth and chlorophyll content of Spirodela polyrrhiza (L.) Schleid as a direct quantitative measure of actual environmental toxicity of tannery effluent.

\section{MATERIALS AND METHODS}

Sample collection : For toxicological tests young Spirodela plants were collected from a local natural shallow pond. After collection, macrophytes were thoroughly cleaned under running water in order to eliminate any remains of sediment and particles and then acclimatized in large troughs for two days. The spent chrome tan liquor samples used in this study were collected in acid-rinsed polyethylene containers from the wet blue section of a tannery located in Central Leather Research Institute (CLRI) complex, Kapurthala Road, Jalandhar, India. The collected samples were brought to the laboratory and stored in a refrigerator at $4^{\circ} \mathrm{C}$ to be used in further studies.

Experimental set-up: Plastic troughs of capacity $1350 \mathrm{ml}$ with surface area of $337 \mathrm{~cm}^{2}$ were used for the experiment. Seven similar sets, each containing $1 \mathrm{~L}$ of different tannery effluent concentrations i.e., 5\%, 10\%, 15\%, 20\%, 40\%, $60 \%, 80 \%$, and $100 \%$ (prepared using tap water) and a control (plants in tap water) were placed. Healthy acclimatized plants with a uniform size and weight $(\sim 14$ g) were selected and inoculated to different concentrations of tannery effluent. Harvesting of samples of S. polyrrhiza was done after every $24 \mathrm{~h}$ for analyzingphytotoxicity of different concentrations of tannery effluent.

Plant analysis: All plants, harvested at the end of each exposure period were washed with tap water, then, rewashed in two lots of distilled water to remove any 
adhering remains of effluent. Further, they were blotted dry under uniform conditions and fresh weight of plant samples was measured using Digital Analytical Balance (ML204, Mettler Toledo). Chlorophyll-a and chlorophyllbmeasurements were made from chilled $80 \%$ acetone extracts of fresh Spirodela plants following the methods of Arnon (1949). OD of the pigment extracts was measured at different wavelengths using UV-VIS Spectrophotometer (UV-1800, Shimadzu).

\section{RESULTS AND DISCUSSION}

The analysis of results of fresh weight of S. polyrrhiza plants after chrome liquor exposure showed an overall gradual decrease in a concentration-duration dependent manner (Table 1). Decrease in the fresh weight of the Spirodela plants with increasing effluent concentration and exposure duration could be explained by increase in the percentage of moisture loss due to increase in the values of osmotic potential owing to the presence of excess salts and is also supported by the observations of Lai et al. (2007); and Neocleous and Minas (2007). Decrease in fresh weight of Spirodela with increasing effluent concentration could also be attributed to degradation of frond and root components e.g. proteins and pigments (Keskitalo et al., 2005) and breaking and decaying of fronds and roots.

The effect of chrome liquor on chl-a, and chl-b present in S. polyrrhiza showed an overall gradual decrease in chl-a (Table 2), chl-b (Table 3) content in a concentration-duration dependent manner. Such decline in chlorophyll concentration of aquatic macrophytes on exposure to different concentrations of tannery effluent is also supported by the observations of Vajpayee et al. (2001) and Sinha et al. (2002).Slight increase in chl-a and chl-b concentration upto $3 \mathrm{~d}$ of exposure at $5 \%$ effluent concentration in S. polyrrhiza could be explained by promotion of photosystem I (PS I) and photosystem II (PSII) activity by low concentrations of $\mathrm{Cr}$ in $5 \%$ concentration of chrome liquor. Such enhancement of activity in plants exposed to $\mathrm{Cr}$-rich wastewater can be attributed to higher flow of electrons to photosystem II required to maintain the physiological status under stress (Dhiret al., 2009).Similar increase in chlorophyll content of Salvinia sp. on exposure to low concentrations of chromium has also been reported by Dhir et al. (2009) and Prado et al. (2010).

Thereafter, the depletion in chlorophyll contents in the plants exposed to different concentrations of chrome liquor might be attributed to both altered chlorophyll biosynthesis due to the disruption of chloroplast phosphorylation (Chandra and Kulshreshtha, 2004) and replacement of Mg ions by

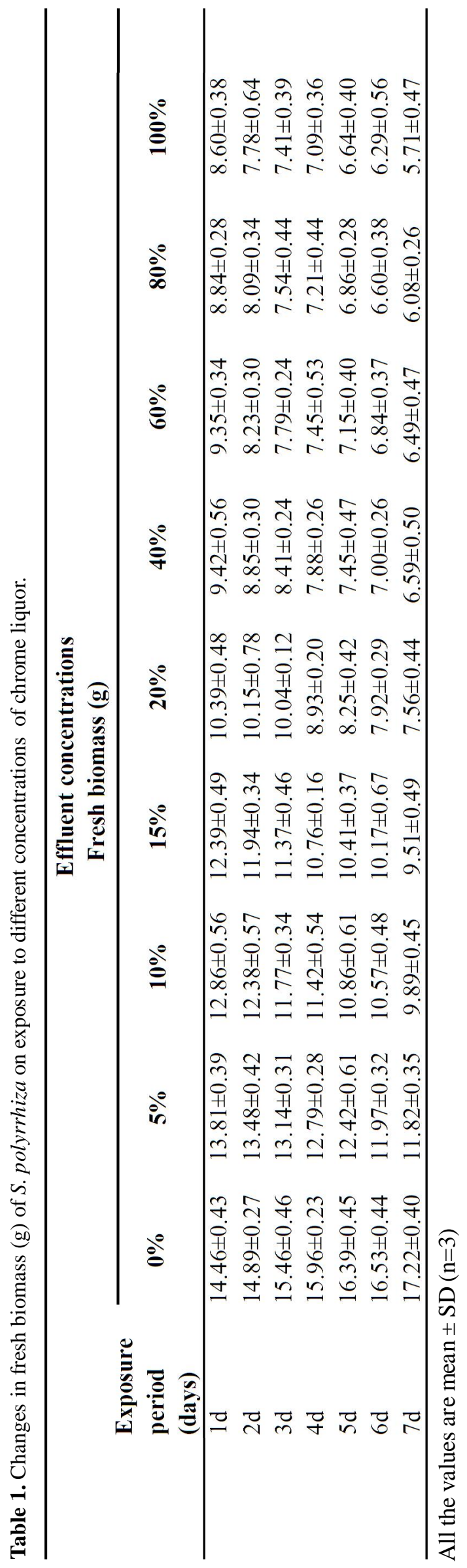




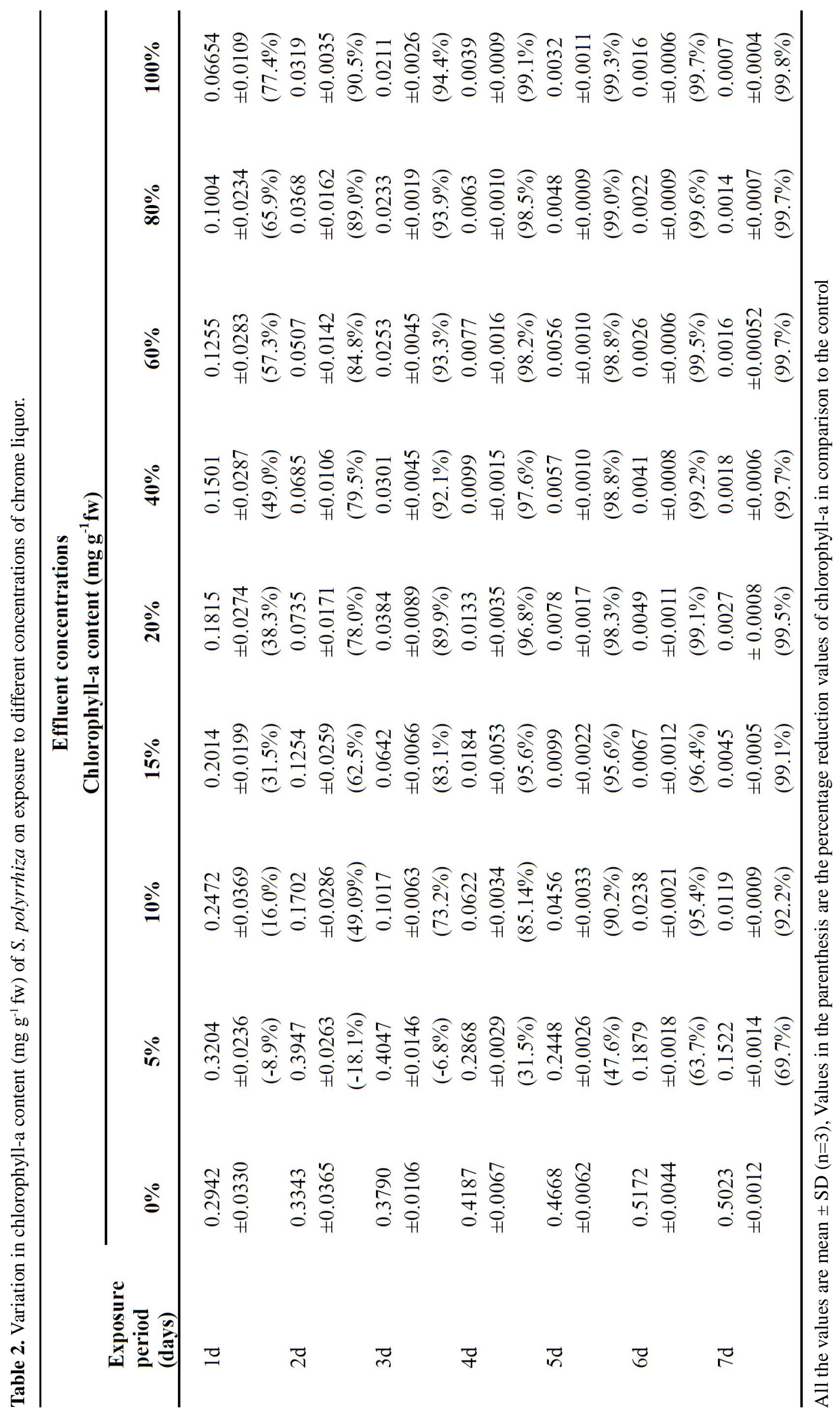




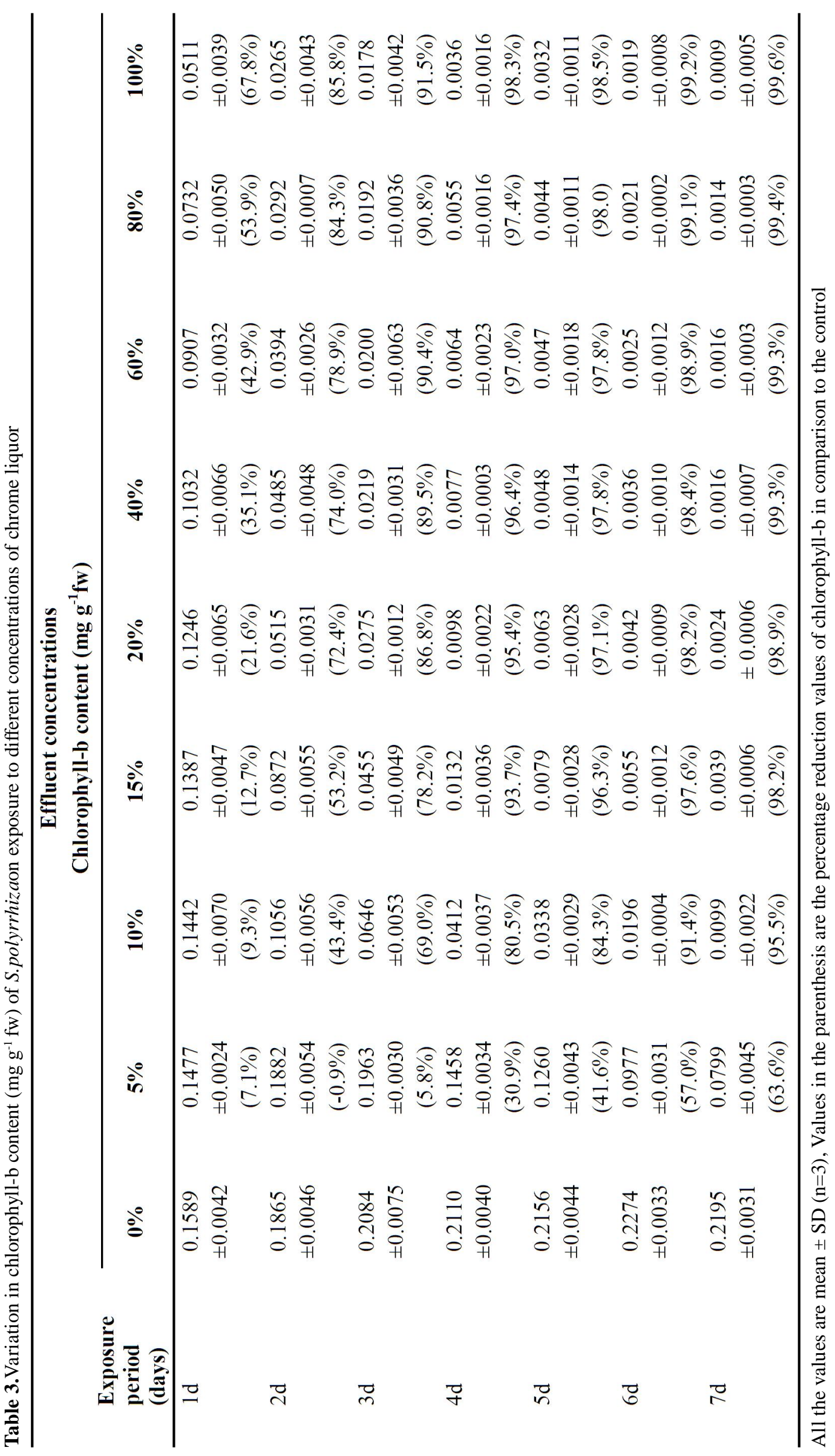


Cr ions (Vajpayee et al., 2001). $\delta$-aminolevulinic acid dehydratase (ALAD) is a metalloenzyme (Chen and Nelands, 1973) and its activity in plants is dependent on availability of $\mathrm{Mg}$. It has been reported that $\mathrm{Cr}$ causes toxicity to ALAD (an enzyme involved in chlorophyll biosynthesis) by impairing $\delta$ aminolevulinic acid (ALA) utilization (Vajpayee et al., 2000). Additionally, exposure to $\mathrm{Cr}$ (VI) normally leads to oxidative damage and increase in succinic dehydrogenase activity (Satyakala andJamil, 1992). It may also change the metalloenzymes of the plant by displacement or replacement of metal ions by its ability to generate reactive oxygen species such as HO and $\mathrm{H}_{2} \mathrm{O}_{2}$ which in turn may cause oxidative stress (Shanker et al., 2005). Further, it has also been reported that $\mathrm{Cr}$ inhibits chlorophyll biosynthesis by causing $\mathrm{Fe}$ deficiency and creating nutrient imbalances.

Analysis of the percentage reduction of chl-a (Table 2) and chl-b (Table 3 ) as compared to the respective control sets revealed greater decline of chl-a than chl-b on exposure to different concentrations of the chrome liquor which could be explained by higher sensitivity of chl-a as compared to chl-b and is also supported by observations of Vajpayee et al. (2000).

\section{Conclusion}

Exposure of S. polyrrhiza (L.) Schleid.to different concentrations of chrome liquor $(5 \%-100 \%)$ showed significant toxic effects on it in a concentration and duration dependent manner, as revealed by reduction in fresh weight, chlorophyll-a and chlorophyll-b in comparison to the control. However, at very low concentration of chrome liquor (5\%) chl-a and chl-b were found to slightly increase up to $3 \mathrm{~d}$ of exposure. In addition, assessment of percentage reduction of chl-a and chl-b in comparison to control demonstrated more sensitive nature of chl-a towards chrome liquor toxicity in comparison to chl-b.

\section{ACKNOWLEDGEMENTS}

This work was performed within the framework of Department of Biotechnology (DBT), Government of India funded research project. The corresponding author (P.M.) gratefully acknowledges the financial support.

\section{REFERENCES}

Arnon, D.I. (1949). Copper enzymes in isolated chloroplast.Polyphenol oxidase in Beta vulgaris. Plant Physiol., 24: 1-15.

Bajza, Z. and Vrcek, I.V. (2001).Water quality analysis of mixtures obtained from tannery waste effluents. E cotoxicology and Environmental Safety, 50 (1): 15-18.

Calheiros, C.S.C., Rangel, A.O.S.S. and Castro, P.M.L. (2008). The effects of tannery wastewater on the development of different plant species and chromium accumulation in
Phragmites australis. Arch. Environ. Contam.Toxicol. 55: 404-414.

Chandra, P. and Kulshreshtha, K. (2004).Chromium accumulation and toxicity in aquatic vascular plants. Botan. Rev. 70: 313-327.

Chen, A. and Nelands, J.B. (1973). Zinc an essential metal ion for beef liver $\delta$-ALA dehydratase. Biochem. Biophys. Res. Comm., 1060-1063.

Dhir, B., Sharmila, P., PardhaSaradhi, P. and Nasim, S.A. (2009). Physiological and antioxidant responses of Salvinia natans exposed to chromium-rich wastewater. Ecotoxicology and Environmental Safety, 72: 1790-1797.

Hafez, A. and El-Manharawy, S. (2004).Design and performance of the two-stage/two-pass RO membrane system for chromium removal from tannery wastewater. Part3.Desalination, 165: 141-151.

Keskitalo, J., Bergquist, G., Gardeström, P. and Jansson, S., (2005).A cellular timetable of autumn senescence.Plant Physiol. 139: 1635-1648.

Kuczynska,A., Wols ka, L.andNamieoenik, J . (2005).Application of biotests in environmental research.Crit. Rev. Anal. C hem., 35: 135-154.

Lai, Q.X., Bao, Z.Y., Zhu, Z.J., Qian, Q.Q. and Mao, B.Z. (2007). Effects of osmotic stress on antioxidant enzymes activities in leaf discs of $\mathrm{P}_{\mathrm{SAG} 12}$-IPT modified gerbera. J ournal of Zhejiang U niver sity Science,8(7): 458-464.

Malaviya, P. and Sharma, A. (2011). Effect of distillery effluent on yield attributes of Brassica napus L. J . Environ. Biol., 32: 385-389.

Malaviya, P. and Singh, A. (2011).Physico-chemical technologies for remediation of chromium-containing waters and wastewaters.Crit. Rev. Environ. Sci. Technol., 41: 1111-1172.

Mwinyihija, M., Meharg, A., Dawson, J., Strachan N.J.C.and Killham, K. (2006). An ecotoxicological approach to assessing the impact of tanning industry effluent on river health. Arch. Environ. Contam. Toxicol. 50: 316-324.

Neocleous, D. and Minas, G.J. (2007). An in-vitro test for salt $(\mathrm{NaCl})$ tolerance of red raspberry (Rubusidaeus L.) cultures. Acta H ort., 741: 289-294.

Prado, C., Rodríguez-Montelongo, L., González, J.A., Pagano, E.A., Hilal, M. and Prado, F. E. (2010). Uptake of chromium by Salvinia minima: Effect on plant growth, leaf respiration and carbohydrate metabolism. J ournal of $\mathrm{H}$ azardous Materials, 177: 546-553.

Satyakala, G. and Jamil, K. (1992). Chromium induced biochemical changes in E ichhornia crassipes (Mart) Solms. andPistia stratiotes L. Bull. Environ. Contam.Toxicol., 48: 921-928.

Shanker, A.K., Cervantes, C., Loza-Tavera, H. and Avudainayagam, S. (2005). Chromium toxicity in plants. Environ. Int., 31: 739-753.

Sinha, S., Saxena, R. and Singh, S. (2002). Comparative studies on accumulation of $\mathrm{Cr}$ from metal solution and tannery effluent under repeated metal exposure by aquatic plants: Its toxic effects. Environ. Monit. Assess., 80: 17-31.

Tahir, S.S. and Naseem, R. (2007). Removal of Cr(III) from tannery waste water by adsorption onto bentonite 
clay. Separation and Purification Technology, 53:312321.

Vajpayee, P., Rai, U.N., Ali, M.B., Tripathi, R.D., Yadav, V., Sinha, S. and Singh, S.N. (2001). Chromium-induced physiologic changes in Vallisneriaspiralis L. and its role in phytoremediation of tannery effluent. Bull. Environ.
Contam.Toxicol., 67: 246-256

Vajpayee, P., Tripathi, R.D., Rai, U.N., Ali, M.B. and Singh, S.N. (2000). Chromium (VI) accumulation reduces chlorophyll biosynthesis, nitrate reductase activity and protein content in Nymphaea alba L. Chemosphere,41: 1075-1082. 